\title{
Randomized Prospective Clinical Study On The Spatz3R Adjustable Intragastric Balloon Treatment With a Control Group: A Large Brazilian Experience
}

Dr. Idiberto Jose Zotarelli Filho, MSc, Ph.D ${ }^{1}$

${ }^{1}$ Affiliation not available

June 9, 2020

\begin{abstract}
AIM: To analyze the results regarding weight loss and complications with Spatz ${ }^{\circledR}$ adjustable intragastric balloon (IGB) in Brazil. METHODS: In this randomized prospective study were included patients that were submitted to Spatz $3^{\circledR}$ adjustable IGB treatment between October 2016 to June 2018 in a private clinic in Rio de Janeiro/Brazil. The patients presented a minimum body mass index $(\mathrm{BMI})$ of $27 \mathrm{~kg} / \mathrm{m}^{2}$. Were analyzed the complications of Spatz ${ }^{\circledR}{ }^{\circledR}$ treatment and BMI reduction, percentage of total weight loss (\%TWL) and \% of excess weight loss (\%EWL). RESULTS: 180 patients underwent implant Spatz ${ }^{\circledR}$ balloon in the period. The patients were randomly separated in one group the Spatz balloon kept the same volume $(600 \mathrm{~mL})$ during all the treatment (Control Group), and adjustment group with $250 \mathrm{~mL}$ more. The complications were $16.14 \%$. No death or major complications happened in the study. The BMI decreased from 39.51 to $32.84 \mathrm{~kg} / \mathrm{m}^{2}$ ( $\mathrm{p}<0.0001$ ), body weight decreased from 111.87 to $90.28 \mathrm{~kg}(\mathrm{p}<0.0001)$ and excess weight diminished from 41.55 to $22.99 \mathrm{~kg}(\mathrm{p}<0.0001)$. The adjustment resulted in a further mean weight loss of $4,35 \mathrm{~kg}$ ( -8 to $17.6 \mathrm{~kg}$ ) and the moment of the procedure was $7.12 \pm 1.63$ months. The upward adjustment group doesn't have a higher \%TWL, \%EWL or a higher BMI reduction when compared to the control group $\left(\mathrm{p}=0.4413, \mathrm{p}=0,9245, \mathrm{p}=0.2729\right.$, respectively).CONCLUSION: This study shows that Spatz $3^{\circledR}$ IGB treatment is an effective procedure for weight reduction, without mortality but with higher morbidity rates when compared to tradition IGBs. The upward adjustment efficacy still needs to be confirmed.
\end{abstract}

Core tip: The present study analyzed the results and complications of patients that underwent overweight treatment with Spatz3 ${ }^{\circledR}$ adjustable balloon, which have as differential the possibility of adjusting the volume during treatment, fact that could lead to a smaller early removal incidence due to intolerance when the downward adjustment is done, and a greater weight loss when the upward adjustment during the treatment is accomplished. However, these benefits occur with a number of complications, although low in gravity, something greater than the traditional balloon.

\section{Ricardo José Fittipaldi-Fernandez ${ }^{1}$, Eduardo Nobuyuki Usuy Júnior $^{2}$, Idiberto José Zotarelli Filho ${ }^{3,4^{*}}$, Cristina Fajardo Diestel ${ }^{5}$, Márcia Regina Simas Torres Klein ${ }^{5}$, Marcelo Falcão de Santana ${ }^{6,7}$, João Henrique Felicio de Lima ${ }^{8}$, Fernando Santos Silva Bastos ${ }^{6,7}$, Newton Teixeira dos Santos ${ }^{9}$}


1. EndogastroRio Clinic, Rio de Janeiro/RJ, Brazil.

2. Gástrica Usuy Clinic, Florianópolis/SC, Brazil.

3. FACERES - Faculty of Medicine of Sao Jose do Rio Preto/SP, Brazil.

4. Zotarelli-Filho Scientific Work, Sao Jose do Rio Preto/SP, Brazil.

5. Department of Applied Nutrition, Nutrition Institute, Rio de Janeiro State University, Rio de Janeiro/RJ, Brazil.

6. IFEC-Instituto Falcão de Endoscopia e Cirurgia (Falcão Institute of Endoscopy and Surgery), Salvador/BA, Brazil.

7. EBMSP-Escola Bahiana de Medicina e Saúde Pública (Bahiana School of Medicine and Public Health), Salvador/BA, Brazil.

8. Endobatel-Digestive endoscopy, Universidade Federal do Paraná-UFPR (Federal University of Paraná), Curitiba/PR, Brazil.

9. $\quad$ NT Santos Serviços médicos (NT Santos-Medical services), Rio de Janeiro/RJ, Brazil.

\section{INTRODUCTION}

The obesity treatment with intragastric balloon (IGB) has already been established as a safe and effective method. ${ }^{[1-3]}$ The volume of the conventional IGB is set at the time of the placement but after that, changes in the volume cannot be done anymore. The balloon can stay in the stomach for a maximum period of 180 days and must be, imperatively removed until this deadline. ${ }^{[4,5]}$ The Spatz3@ ${ }^{\circledR}$ liquid adjustable balloon was approved in May 2010 in all 27 countries of the European Union for patients with body mass index (BMI) more than $27 \mathrm{~kg} / \mathrm{m}^{2}$ that failed previous attempts at weight loss. In November 2014, the Spatz $3^{\circledR}$ balloon was approved for clinical use in Brazil. Today Spatz3@ ${ }^{\circledR}$ IGB is in its third generation, is a safer device and easier to use compared to earlier generations. ${ }^{[6]}$

According to the Tarpon Springs conference held in 1987 in Florida ${ }^{[7]}$, it was defined as being ideal for the IGB the following criteria:1) Have variable filling volume capacity (400-700mL); 2) Be fluid filled (water or saline); 3) Have a radiopaque marker for control of follow-up; 4) Be made from tough and durable material, preventing leakage and 5) Have smooth surface. According to these criteria, the Spatz ${ }^{\circledR}$ IGB, when compared to conventional one, is better according to the first criterion, since its volume can be controlled throughout the treatment, and not only at the implatation. ${ }^{[8]}$ However, it is worse according to the last issue, since it does not have a completely smooth surface, because it has a "tail", the site of filling valve insertion. ${ }^{[8]}$

The two main differentials of Spatz3 ${ }^{\circledR}$ IGB are post implantation volume control and a maximum treatment period of 360 days. ${ }^{[2,7,8]}$ Regarding the volume, it is feasible to adjust the balloon - upward or downward - during all the treatment. The balloon may have its volume reduced in cases of intolerance (excessive and/or persistent vomiting for more than seven days). Withdraws from 100 to $300 \mathrm{~mL}$ of the IGB volume, improves the symptoms and allow the patient to continue the treatment. The balloon also may have its volume increased during the treatment, in a predetermined date, or when the patient reports a decrease in satiety. The upward setting in balloon volume may increases the effect of the balloon on weight loss due to increased satiety and greater restriction of food intake. ${ }^{[8]}$ The maximum stay of 360 days results in a sustained weight loss for one year and a longer period of treatment provides more time for the patient to perform alimentary reeducation with the balloon support. ${ }^{[9]}$

Although adjustable IGB seems to have several potential benefits compared to conventional balloons (better patient tolerability, gradual effective weight loss and longer duration of implantation) ${ }^{[23]}$, to date, few studies 
(some with a small number of participants) evaluated its safety and efficacy. ${ }^{[2,8,14,27]}$ Moreover, there are some reports questioning its long-term safety. ${ }^{[24-26]}$

The aim of this study was to analyze the results regarding weight loss and complications with Spatz $3^{\circledR}$ adjustable IGB in a private center in Brazil.

\section{METHODS}

\section{Study design}

In this randomized prospective study were included patients that were submitted to Spatz ${ }^{\circledR}$ (Genco et al., 2013) ${ }^{[2]}$ (Spatz ABS-Spatz FGIA, Inc., Jericho, NY, USA).

adjustable IGB treatment between October 2016 and June 2018 in a private clinic (EndogastroRio) in Rio de Janeiro/Brazil.

\section{Inclusion and exclusion criteria}

The inclusion criteria were: adult and elderly patients with a BMI [?] $27 \mathrm{~kg} / \mathrm{m} 2$ who failed to lose weight in clinical well conducted treatments of overweight/obesity. The exclusion criteria were adolescents, patients with obesity of hormonal or genetic causes, alcohol or illicit drug abusers, those with a known malignancy and pregnant women.

A preliminary interview established medical history, including previous attempts to lose weight, comorbidities, and the impact of their obesity, both socially and psychologically.

\section{Randomization groups}

After the randomization process performed by the Minitab(r) software, 86 patients were allocated to the upward adjustment group and 94 patients were allocated the non-adjustment group (control group), with a total of 180 .

\section{Ethical Considerations}

The study was reviewed and approved by Clinical Institutional Review Board and was conducted in accordance with the ethical standards laid out in the 1964 Declaration of Helsinki and its later amendments or comparable ethical standards. Informed consent was obtained from all individual participants included in the study.

\section{Interventions - Balloon placement}

Balloon insertion was performed after a diagnostic endoscopy in order to detect pathologies that contraindicate balloon placement, such as active peptic ulcer, grade C-D esophagitis, large volume hiatal hernia, esophageal/fundus varices, esophageal strictures and prior gastric surgery.

The endoscopy procedure was realized under deep sedation without endotracheal intubation, with continuous oxygen support of $5 \mathrm{~L} / \mathrm{min}$ and under anesthesiologist supervision. Since there were no impediments, the procedure to implant the balloon was initiated.

In the conventional technique, recommended by the manufacturer, the insertion of the Spatz $3^{(\mathrm{r})}$ balloon is together with the endoscope (the balloon goes attached to the scope). In the balloon kit, there is a "condom", which is connected to the scope tip, and with the condom wrapped, the balloon is placed next to the device. Then the condom takes place over the balloon, attaching it to the device. The assembly (balloon + scope) is then heavily lubricated with appropriate gel and both endoscopic and balloon together are introduced into the patient, gently and parsimoniously. In the gastric cavity, it is recommended to perform the rear view, to confirm that the balloon is fully gastric and have not detached from the endoscope during its introduction, thus avoiding the risk of complications from balloon inflation in the esophagus. The balloon inflation was under direct vision remaining endoscope in rear view. The balloon was inflated with saline $(3 \%)$ and with $10 \mathrm{~mL}$ of $4 \%$ methylene blue. The initial balloon volume was settled at $600 \mathrm{~mL}$. 
After the inflation procedure, the filling catheter was pulled-up until the externalization of the balloon valve through the patient's mouth. At this moment point it is important to introduce the finger through the patient's mouth placing it over the base of the tongue. The catheter and the valve slide over the finger, protecting the base of the tongue from a possible damage caused by the passage of the valve and avoiding a local bleeding. Then the catheter was disconnected from the valve, which was then covered with a suitable cap with a blue nylon loop on its top. Holding the loop, the valve was gently returned into the patient, releasing it at the oropharynx. So the scope was used to position the valve into the stomach then the balloon was visually inspected to detect possible leaks or valve malfunctions and to confirm the correct position in the gastric fundus. If a leakage was detected a prompt replacement of the defective balloon was conducted.

\section{Follow up}

After IGB insertion and before discharge, patients remained for almost 1-2h in the anesthesia recovery room until full recovery from sedation. Instructions were provided for a 5-day liquid diet (with progressive increase in the ingested volume). On the sixth day, a semi-solid diet was prescribed and, after the thirteenth day, solids were introduced into a $1200 \mathrm{kcal} /$ day diet. Afterwards (maximum 15 days after IGB placement), the patients were referred to a personalized nutritional counseling, when an individual diet was prescribed with a range of 10-15 kcal $/ \mathrm{kg} /$ day. Monthly follow up with a multidisciplinary team (dietitian, psychologist and doctor) was offered to all patients.

In the first three days after balloon insertion, patients were instructed to use three anti emetic drugs (metoclopramide, ondansetron and dimenhydrinate), an anti-foaming drug (dimethicone), and analgesics/antispasmodics (escopolamine plus dipyrone and acetaminophen). All patients were instructed to use proton pump inhibitor (PPI; pantoprazole magnesium) throughout the treatment: a double dose in the first month (80mg) and a full dose from the second month (40mg) to the end of the treatment. Additionally, vitamin and mineral supplementation and probiotics (Lactobacillus acidophilusLA 16) were given to all patients during the entire treatment.

\section{Balloon adjustment}

Patients who were intolerant to the balloon could have its volume adjusted downward, and those in the adjustment group had the volume adjusted upward by a standard volume of $250 \mathrm{~mL}$ in the course of the treatment.

On the five days before the balloon adjustment, patients were instructed to eat a liquid diet. The procedure was done under deep intravenous sedation. The endoscopy was held, and the following sequential steps:

1. Seizure valve cover blue nylon loop strap with a foreign body forceps;

2. Pull out the scope carrying the valve together, unscrews the protective cover, and connects the adjustment catheter (the same one used for filling in the implant);

3. The balloon volume is then reduced (aspirating the liquid inside the balloon through the catheter with $60 \mathrm{~mL}$ syringe) or increased (by injecting fluid through the catheter using a $60 \mathrm{~mL}$ syringe);

4. The adjustment catheter is then pulled up to externalize the valve through the mouth in the same way of the balloon implant and then, disconnected from the valve;

5. The protective cover is placed again;

6. Return the valve to the gastric cavity.

\section{Balloon removal}

Removal was routinely planned for 360 days, but occurred with a minimum of 270 and maximum of 390 days after balloon implantation. Removal was preceded by a five day clear-fluid diet, in order to minimize the risk of residual food entering the trachea. Deep intravenous anesthesia without tracheal intubation was used, 
with the patient in a lateral decubitus position. The presence of solid food waste in the stomach resulted in the cancelation of the procedure and another was scheduled with adequate preparation.

All the liquid content in the mucosal lake was aspirated. After insertion of the gastroscope in the stomach, a needle-catheter was inserted down the working channel of the gastroscope and introduced inside the balloon after puncture. The needle was withdrawn with vacuum applied to completly empty the balloon. Following intravenous administration of scopolamine for relaxation of the lower esophageal sphincter, the catheter was removed and the balloon was grasped with a polypectomy snare on the base of the tail, and slowly extracted through the esophagus. No cases of aspiration were observed during this procedure. After balloon removal, a endoscopy was performed in order to detect possible damage caused by the passage of balloon

\section{Outcomes}

The outcomes evaluated in the present study included safety indicator (treatment complications) and efficacy indicators such as weight loss $(\mathrm{kg})$, change in BMI $\left(\mathrm{kg} / \mathrm{m}^{2}\right), \%$ total weight loss (\%TWL) and \% excess weight loss (\% EWL) during balloon use (minimum 270 days). Anthropometric measures were obtained at baseline (day of IGB insertion) and at the end of the study (day of IGB removal). Height was measured with a stadiometer accurate to $+-0.5 \mathrm{~cm}$ and weight was obtained with a digital scale accurate to $+-0.1 \mathrm{~kg}$ (Filizola S.A., Sao Paulo, SP, Brazil), after participants without shoes and wearing light clothing, attempted to empty their bladder. Body mass index (BMI) was calculated using the standard equation $\left(\mathrm{kg} / \mathrm{m}^{2}\right)$. BMI cutoff points were used to classify the participants as overweight (25-29.9), class I obese (30-34.9), class II obese (35-39.9) and class III obese ([?]40). ${ }^{[10]}$ Excess weight (EW) was determined as the amount of weight that is in excess of the ideal body weight (determined as a BMI of 24.9). The success of the treatment was evaluated according two criteria:

1. The percentage of excess weight loss (\%EWL): patients who did not achieved the goal of the treatment $(<20 \%)$, those with success of treatment $(20-50 \%)$ and those who had high success $(>50 \%)$. [11]

2. And the percentage of total weight loss (\%TWL): patients who did not achieved the goal of the treatment $(<10 \%)$, and those with success of treatment ([?]10\%).[11]

\section{Statistical analysis}

For data analysis, a database was being built on the Microsoft Excel spreadsheet that was being exported to the Minitab 18(r) statistical program (version 18, Minitab, LLC, State College, Pennsylvania, USA) (Minitab(r)) and also to OriginPro(r) 9 (DPR Group, Inc., Northampton, Massachusetts, USA) (Moberly, Bernards, Waynant, 2018). TheKolmogorov-Smirnov test for normality was used to confirm the normal distribution of the variables. The results are presented as mean +- standard deviation for numerical variables and absolute numbers (percentage) for categorical variables. A paired Student's t test was used for comparisons between values obtained at the baseline and at the end of the treatment and non paired test for comparisons between patients that did the balloon upward adjustment and those that didn't. Comparisons between different reductions in Total Weight Loss and Excess Weight Loss, with and without Spatz3(r) adjustment, were made with One-Way and variance (ANOVA) analysis. Multivariate analysis (Dendogram) was also performed to find out the degree of similarity (\%) between the mean of \%TWL and \%EWL groups. In all statistical analyzes, a p-value $<0.05$ was considered to be significant.

\section{RESULTS}

The complications were analyzed taking into account the total number of patients in the study period ( $\mathrm{n}=180$, $34.4 \%$ Males). Complications during treatment are shown in Table 1 . There were no deaths resulting from complications.

Of these patients $(\mathrm{n}=180)$, eight $(4.44 \%)$ were intolerant to the balloon between two and four weeks and agreed to volume adjustment. Four did the downward adjustment in the second week after implantation and four in the fourth week. The range of volume that was removed was $220 \mathrm{~mL}$ (150-400 mL). 86 patients did the upward adjustment and from this, three $(6.52 \%)$ presented intolerance after this procedure. All of the 
patients were submitted one week later to downward adjustment of $50 \%$ of the volume that was placed in upward adjustment $(150-210 \mathrm{~mL})$ and kept in treatment.

The baseline patient characteristics are reported in Table 2 .

Changes in body weight, BMI and EWL are shown in Table 3 . The data is reported in the total group of patients and separately for those who did the upward adjustment $(n=86)$ and those who didn't $(n=94)$. There was a significant decrease in all these nutritional parameters during the study period.

Eighty-six patients $(47.78 \%)$ underwent upward adjustment. The adjustment resulted in a further mean weight loss of $4.2 \mathrm{~kg}$ ( -9 to $20 \mathrm{~kg}$ ), the standard upward volume was $250 \mathrm{~mL}$ and the moment of the procedure was 7.06+-1.64 months (2-10). The upward adjustment group doesn't have a higher \%TWL, \%EWL or a higher BMI reduction when compared to the group that did not $(\mathrm{p}=0.4413, \mathrm{p}=0,9245, \mathrm{p}=0.2729$, respectively).

In terms of \%EWL, fourty patients $(22.22 \%)$ did not meet the treatment goal $(\mathrm{EWL}<25 \%)$. According to the \%TWL, fifty two patients $(28.89 \%$ ) did not achieve treatment success (TBWL $<10 \%$ ). Twenty one patients $(11.66 \%$ ) finished the study under BMI of $25 \mathrm{~kg} / \mathrm{m} 2$ (Table 4 ). The success rate was superior in patients that did the upward adjustment (77.91\%) compared to those who did not $(64.89 \%)$.

Figures 1 and 3 show the Dendogram graphs with the degree of percentage similarity between the values of the average reduction of the total weight loss in kilograms (TWL) and the excess weight loss in kilograms (EWL), with and without adjustment of Spatz3(r), with values of $77.07 \%$ and $76.44 \%$, respectively. Figures 2 and 4 showed, using the Box-Plot graph, the intervals, mean and median of the TWL and the EWL reduction values, with and without Spatz3(r) adjustment, and the p-value values were, respectively, $\mathrm{p}=$ $0.056>0.05$, and $\mathrm{p}=0.058>0.05$, both with no statistically significant difference.

\section{DISCUSSION}

The IGB treatment is a well-recognized therapy for overweight/obesity ${ }^{[2,3,12,13]}$ and have been successfully used for weight loss for the last 20 years. ${ }^{[14]}$ The mechanism of action of IGB is multifactorial and incompletely understood. ${ }^{[21,22]}$ Theoretically IGB affects both the stretch receptors and the gastric capacity, increases satiety while decreasing the residual volume available for food, as well enlarging the gastric emptying time, and therefore could be considered a restrictive procedure to treat obesity. ${ }^{[15]}$ Other proposed mechanism include changes in appetite-regulating hormones (decrease in ghrelin and leptin and increase in CCK concentrations); however there are conflicting reports. ${ }^{[21,22]}$ The better results with IGB occur when the treatment is associated with behavioral changes. . $^{2,3,12,13]}$

However, it is not possible to define the ideal balloon size for a specific patient, as the threshold for nausea, vomiting and/or abdominal pain are not measurable or predictable. ${ }^{[8]}$ Moreover, a decrease in IGB efficacy in promoting weight loss due to a reduction of the satiety effect after three months has been demonstrated in some studies. ${ }^{[15-17]}$. However, the traditional IGB have some limitations: a decrease in the efficacy in promoting weight loss after 2 to 3 months, a maximum length of treatment is 6 -month and a significant rate of complications during the early implantation period (nausea, vomiting, and discomfort), leading balloon extraction in $4-5 \%$ of patients. ${ }^{[5,12,15-17]}$ It is not possible to define the ideal balloon size for a specific patient, as the threshold for nausea, vomiting and/or abdominal pain are not measurable or predictable. ${ }^{[8]}$ The introduction of the Spatz $3^{(\mathrm{r})}$ Adjustable Balloon system offers features that address these limitations.

The main complication was the early removal of the balloon (removal before nine months post implantation). However, most of these $(\mathrm{n}=12,6.66 \%)$ were not due to adaptation symptoms, but for various other reasons, such as desire to give up the treatment, weight loss considered insufficient by the patient, and psychological intolerance (desire to eat, desire to remove the foreign device from the inside of the body). Only two removals $(1.11 \%)$ were performed due to severe symptoms (excessive vomiting) in patients who did not wish to do the downward adjustment and decided to quit the treatment. The incidence of early removal in the present study was $7.77 \%$, being similar to that observed in other studies conducted with Spatz, Machytka et al (2014) ${ }^{[6]}$ observed $7.79 \%$ and Brooks et al (2014) ${ }^{[14]} 5.47 \%$. However, this rate is higher than the observed in studies 
conducted with conventional IGB, Genco et al (2005) ${ }^{[9]}$ observed $0.44 \%$, Lopez-Nava et al $(2011)^{[12]} 0.8 \%$ and Sallet et al $(2004)^{[1]} 3.4 \%$. It is important to note that from the 14 early removals in this study, only $2(1.24 \%)$ were due to early intolerance, approaching to the results previously described. Furthermore, patients who underwent downward adjustment $(\mathrm{n}=8 ; 4.44 \%)$, all, without exception, completed the minimum 9 months treatment, similar to what was observed in other Spatz ${ }^{(\mathrm{r})}$ IGB studies. ${ }^{[6,14]}$ Thus, it seems that the downward balloon adjustment may contribute to a better adaptation and a lower early removal rate.

There were three cases $(1.66 \%$ ) of spontaneous deflation before nine months post implantation, the minimum time length established for treatment, with immediate replacement of the defective balloon and permanence in the treatment. This index is lower than the observed by Machytka et al $(2011)^{[8]}$ in Spatz $^{(\mathrm{r})}$ initial series (11.11\%), but they used first and second generation Spatz ${ }^{(\mathrm{r})}$ balloons, while in the present study we used only the third generation, that was described as having easier implantation and extraction procedures which are less complicated with fewer steps. ${ }^{[6]}$ When compared with the study conducted by Brooks et al $(2014)^{[14]}$, that also used third generation Spatz ${ }^{(\mathrm{r})}$ balloons, the spontaneous deflation index of the present study $(1.66 \%)$ was lower (vs. $4.1 \%$ ).

In one $(0.55 \%)$ patient it was detected, at the tenth week of treatment, gas production inside the balloon, when the patient started to vomit again. An x-ray of the abdomen was performed, being observed air-fluid level inside the balloon. The balloon was then completely emptied and filled again with $3 \%$ sterile saline plus $10 \mathrm{~mL}$ of $4 \%$ methylene blue, the patient remained in the treatment without any problems and without the need for removal or replacement of the balloon. This complication has not been reported in any other Spatz $^{(\mathrm{r})}$ balloon study, and is believed to have happened, possibly, due to contamination of the liquid inside the balloon by anaerobic bacteria from the gastrointestinal tract.

There was one case $(0.55 \%)$ of upper gastrointestinal bleeding without hemodynamic repercussions. At the endoscopy, was detected the presence of a tear in the gastroesophageal junction due to excess vomiting after an upward balloon adjustment. It was then removed half of the upward adjustment volume, with prompt improvement in symptoms and permanence in the treatment, with no need for balloon removal. Machytka et al (2014) ${ }^{[6]}$ also showed one case $(1.29 \%)$ of upper gastrointestinal bleeding, but due to gastric ulcer.

Regarding gastric ulcers, six $(3.33 \%)$ were diagnosed in the gastric antrum lesser curvature. One of them $(0.55 \%)$ needed the removal of the balloon due to intense pain and depth of the lesion. When asked, the patient said that was not taking the prescribed proton pump inhibitor (PPI). Five $(2.77 \%)$ other ulcers were asymptomatic and were diagnosed during treatment (during an adjustment procedure) or at the removal of the balloon. All of them were treated conservatively with increasing PPI dose and sucralfate, with adequate response and wound healing. The incidence of ulcers is higher in studies using Spatz ${ }^{(\mathrm{r})}$ balloons (Machytka et al $(2014)^{[6]}-1.29 \%$ and Brooks et al $\left.(2014)^{[14]}-2.73 \%\right)$ than in studies using traditional balloons (Genco et al $(2005)^{[2]}-0.2 \%$ and Sallet et al $\left.(2004)^{[1]}-0 \%\right)$. This can be possibly explained by the fact that the Spatz ${ }^{(\mathrm{r})}$ balloon does not have a completely smooth surface, since it has a tail, which acts as a compression point on gastric mucosa ${ }^{[8]}$, and could generate a pressure ulcer. There was in this study no case of gastric perforation, esophageal perforation or death.

Weight loss has traditionally been the main outcome measure of the efficacy of IGB treatment and was observed in the majority of our patients. The \%EWL in the present study was similar or slightly superior than that observed in other Spatz ${ }^{(\mathrm{r})}$ series reported in the literature (Table 5 ).

However the weight loss after the upward adjustment in the present study was lower than in other Spatz ${ }^{(\mathrm{r})}$ studies (Table 5 ). This can be possibly attributed to the fact that in our study the upward adjustment was performed latter $(7.12+-1.63$ months $)$ than in the studies conducted by Machytka et al (2014) ${ }^{[6]}$ and Brooks et al (2014) ${ }^{[14]}$, in which the mean adjustment time was 4.1 and 5.8 months, respectively, allowing more time for further weight loss. Or, more feasible, the upward adjustment is not effective in promoting extra weight loss.

In this study, the upward adjustment was done in all patients in the upward adjustment group. The incidence of this procedure $(47.77 \%, \mathrm{n}=86$ of 180$)$ was higher compared to $\mathrm{Spatz}^{(\mathrm{r})}$ series of Genco et al (2013) ${ }^{[9]}$ and 
Machytka (2014) ${ }^{[6]}$, with $22.5 \%$ and $19.48 \%$ of upward adjustments, mainly by weight plateau. However, the percent of excess weight loss of patients that did the adjustment was not significantly higher when compared to those that did not. Similarly, Genco et al (2013) ${ }^{[9]}$ reported that final mean BMI of the patients who did upward adjustment was higher than patients with Spatz ${ }^{(\mathrm{r})}$ who did not, but there was no statistical significance and they highlighted that this observation was in a few number of patients and needed to be confirmed.

Considering our study model, the sample size is limited, but reasonable for a prospective study, and larger than other studies with this balloon. This study has limitations and the major one is the absence of a sham group, difficult to be done in a private center. However, in our opinion, the possibility to evaluate the real life tolerance, efficacy and complications associated with the use of Spatz $3^{(\mathrm{r})}$ IGB, and the presence of a control group (non adjustment group) compensate the absence of a sham group.

The long lasting treatment (one year) allows a longer nutritional counseling, in order to increase patient compliance and to reinforce the necessity of behavior changes from the very early stages of treatment. Patients should be aware that is important not only to lose weight, but to keep a sustained loss, as described by different authors. ${ }^{[18-20]}$ Even with one year treatment, the majority of the patients still have obesity (final BMI $32.84 \mathrm{~kg} / \mathrm{m} 2$ only four patients with BMI $<25 \mathrm{~kg} / \mathrm{m} 2$ ). The Spatz3 ${ }^{(\mathrm{r})}$ use does not represent a definitive treatment to obesity and is necessary to be associated with permanent behavioral changes and probably a second balloon treatment. At this time, there is no contraindication to use the Spatz $3^{(\mathrm{r})}$ for a sequential therapy as traditional IGBs. ${ }^{[9]}$

Therefore, this study shows that Spatz $3^{(\mathrm{r})}$ IGB treatment is an effective procedure for weight reduction, without mortality but with higher morbidity rates when compared to tradition IGBs. Currently, the IGBs offer a safe and effective weight loss option for patients. It is cristal clear that the downward adjustment reduces the incidence of early removals due to intolerance. However, it is not clear if the upward adjustment is effective in promote extra weight loss, since all the analyzed parameters did not show statistical difference between both groups. On the other hand, the adjustment group showed a slightly higher treatment success rate. Additional clinical trials are necessary to better understand the difficulties and problems with Spatz $3^{(\mathrm{r})}$ IGB use, and the efficacy of the upward adjustment.

\section{Funding}

Supported by EndogastroRio Clinic, Rio de Janeiro-RJ, Brazil.

\section{Conflict-of-interest statement}

The authors declare they have no conflict of interest.

\section{Data sharing statement}

No additional data are available

\section{REFERENCES}

1. Sallet JA, Marchesini JB, Paiva DS, Komoto K, Pizani CE, Ribeiro ML, Miguel P, Ferraz AM, Sallet PC. Brazilian multicenter study of intragastric balloon. Obes Surg. 2004;14:991-8. [PMID:15329191]

2. Genco A, Bruni T, Doldi SB, Forestieri P, Marino M, Busetto L, Giardiello C, Angrisani L, Pecchioli L, Stornelli P, Puglisi F, Alkilani M, Nigri A, Di Lorenzo N,Furbetta F, Cascardo A, Cipriano M, Lorenzo M, Basso N. BioEnterics Intragastric balloon: the Italian experience with 2,515 patients. Obes Surg. 2005;15:1161-4. [PMID:16197790]

3. Forlano R, Ippolito AM, Iacobellis A, Merla A, Valvano MR, Niro G, Annese V, Andriulli A. Effect of the BioEnterics intragastric balloon on weight, insulin resistance, and liver steatosis in obese patients. Gastrointest Endosc 2010;71:927-33.[PMID:19863955 / DOI:10.1016/j.gie.2009.06.036.]

4. Wahlen CH, Bastens B, Herve J, Malmendier C, Dallemagne B, Jehaes C, Markiewicz S, Monami B, Weerts J. The Bio Enterics Intragastric Balloon (BIB): how to use it. Obes Surg 2001; 11: 524-7. [PMID:11501368] 
5. Imaz I, Martinez-Cervell C, Garcia-Alvarez EE, Sendra-Gutierrez JM, Gonzalez-Enriquez J. Safety and effectiveness of the intragastric balloon for obesity. A meta-analysis. Obes Surg. 2008;18:841-6. [PMID:18459025 / doi: 10.1007/s11695-007-9331-8.]

6. Machytka E, Brooks J, Buzga M and Mason J. One year adjustable intragastric balloon: safety and efficacy of the Spatz3 adjustable balloons [v1; ref status: approved with reservations 2, http://f1000r.es/471] F1000Research 2014, 3:203 (doi:10.12688/f1000research.5099.1)

7. Schapiro M, Benjamin S, Blackburn G, Frank B, Heber D, Kozarek R, Randall S, Stern W.Obesity and the gastric balloon: a comprehensive workshop. Tarpon Springs, Florida, March 19-21, 1987. Gastrointest Endosc 1987; 33: 323-7. [PMID:3653653]

8. Machytka E, Klvana P, Kornbluth A, Peikin S, Mathus-Vliegen LE, Gostout C, Lopez-Nava G, Shikora S, Brooks J. Adjustable intragastric balloons: a 12-month pilot trial in endoscopic weight loss management. Obes Surg. 2011, 21(10):1499-507. [PMID:21553304 / doi: 10.1007/s11695-011-0424-z.]

9. Genco A, Dellepiane D, Baglio G, Cappelletti F, Frangella F, Maselli R, Dante MC, Camoirano R, Lorenzo M, Basso N. Adjustable intragastric balloon vs non-adjustable intragastric balloon: case-control study on complications, tolerance, and efficacy. Obes Surg. 2013 Jul;23(7):953-8. [PMID:23526067 / doi: 10.1007/s11695-013-0891-5.]

10. Jensen MD, Ryan DH, Apovian CM, Ard JD, Comuzzie AG, Donato KA, Hu FB, Hubbard VS, Jakicic JM, Kushner RF, Loria CM, Millen BE, Nonas CA, Pi-Sunyer FX, Stevens J, Stevens VJ, Wadden TA, Wolfe BM, Yanovski SZ. 2013 AHA/ACC/TOS guideline for the management of overweight and obesity in adults: a report of the American College of Cardiology/American Heart Association Task Force on Practice Guidelines and The Obesity Society. J Am Coll Cardiol 2014; 63:2985-3023. [PMID:24239920 / doi: 10.1016/j.jacc.2013.11.004.]

11. Herve J, Wahlen CH, Schaeken A, Dallemagne B, Dewandre JM, Markiewicz S, Monami B, Weerts J, Jehaes C. What Becomes of Patients One Year after the Intragastric Balloon has been Removed? Obes Surg 2005, 15, 864-870 [PMID:15978160]

12. Lopez-Nava G, Rubio MA, Prados S, Pastor G, Cruz MR, Companioni E, Lopez A. BioEnterics(r) Intragastric Balloon (BIB(r)). Single Ambulatory Center Spanish Experience with 714 Consecutive Patients Treated with One or Two Consecutive Balloons. Obes Surg 2011 21:5-9. [PMID:20306153 / doi: 10.1007/s11695-010-0093-3.]

13. Stimac D, Majanović SK, Turk T, Kezele B, Licul V, Orlić ZC. Intragastric balloon treatment for obesity: results of a large single center prospective study. Obes Surg 2011;21:551-5. [PMID:21170685 / doi: 10.1007/s11695-010-0310-0.]

14. Brooks J, Srivastava ED, Mathus-Vliegen EM. One-year adjustable intragastric balloons: results in 73 consecutive patients in the U.K. Obes Surg. 2014; 24(5):813-9 [PMID:24442419 / doi: 10.1007/s11695014-1176-3.]

15. Mion F, Napoléon B, Roman S, Malvoisin E, Trepo F, Pujol B, Lefort C, Bory RM. Effects of intragastric balloon on gastric emptying and plasma ghrelin levels in nonmorbid obese patients. Obes. Surg. 2005; 15: 510-6. [PMID:15946431]

16. Mui WL, Ng EK, Tsung BY, Lam CH, Yung MY. Impact on obesity-related illnesses and quality of life following intragastric balloon. Obes Surg. 2010;20(8):1128-32.[ PMID:19015930 / doi: 10.1007/s11695008-9766-6.]

17. Al Kahtani K, Khan MQ, Helmy A, Al Ashgar H, Rezeig M, Al Quaiz M, Kagevi I, Al Sofayan M, Al Fadda M. Bio-enteric intragastric balloon in obese patients: a retrospective analysis of King Faisal Specialist Hospital experience. Obes Surg.2010;20(9):1219-26.[PMID:18752030 / doi: 10.1007/s11695008-9654-0.]

18. Kotzampassi K, Grosomanidis V, Papakostas P, Penna S, Eleftheriadis E. 500 Intragastric Balloons: What Happens 5 Years Thereafter. Obes Surg 2012; 22:896-903.[ PMID:22287051 / doi: 10.1007/s11695012-0607-2.]

19. Herve J, Wahlen CH, Schaeken A, Dallemagne B, Dewandre JM, Markiewicz S, Monami B, Weerts J, Jehaes C. What Becomes of Patients One Year after the Intragastric Balloon has been Removed? Obes Surg 2005, 15, 864-870. [PMID:15978160] 
20. Dastis NS, François E, Deviere J, Hittelet A, Ilah Mehdi A, Barea M, Dumonceau JM. Intragastric balloon for weight loss: results in 100 individuals followed for at least 2.5 years. Endoskopie Heute 2009;22:151-8. [PMID:19588283 / doi: 10.1055/s-0029-1214826]

21. Papademetriou M, Popov V. Intragastric Balloons in Clinical Practice. Gastrointest Endosc Clin N Am. 2017 Apr;27(2):245-256. Doi: 10.1016/j.giec.2016.12.006.

22. Laing P, Pham T, Taylor LJ, Fang J. Filling the Void: A Review of Intragastric Balloons for Obesity. Dig Dis Sci. 2017 Jun;62(6):1399-1408. Doi: 10.1007/s10620-017-4566-2. Epub 2017 Apr 18.

23. Sampath K, Dinani AM, Rothstein RI. Endoscopic Devices for Obesity. Curr Obes Rep. 2016 Jun;5(2):251-61. Doi: 10.1007/s13679-016-0217-8.

24. Seung Han Kim, Hoon Jai Chun, Hyuk Soon Choi, Eun Sun Kim, Bora Keum, and Yoon Tae Jeen. Current status of intragastric balloon for obesity treatment. World J Gastroenterol. 2016 Jun 28; 22(24): 5495-5504. Published online 2016 Jun 28. Doi: 10.3748/wjg.v22.i24.5495.

25. Daniel F, Abou Fadel C, Houmani Z, Salti N. Spatz 3 Adjustable Intragastric Balloon: Long-Term Safety Concerns. Obes Surg. 2016 Jan;26(1):159-60. Doi: 10.1007/s11695-015-1897-y.

26. Yap Kannan R, Nutt MR. Are intra-gastric adjustable balloon system safe? A case series. Int J Surg Case Rep. 2013;4(10):936-8. Doi: 10.1016/j.ijscr.2013.07.025. Epub 2013 Aug 13.

27. Russo T, Aprea G, Formisano C, Ruggiero S, Quarto G, Serra R, Massa G, Sivero L.BioEnterics Intragastric Balloon (BIB) versus Spatz Adjustable Balloon System (ABS): Our experience in the elderly. Int J Surg. 2017 Feb;38:138-140. Doi: 10.1016/j.ijsu.2016.06.013. Epub 2016 Jun 21.

Table 1. Complications of Spatz $3^{\circledR}$ Balloons.

\begin{tabular}{ll}
\hline Complications & Frequency* $(\mathbf{n}=\mathbf{1 8 0})$ \\
\hline $\begin{array}{l}\text { Spontaneous deflation } \\
\text { Early retrieval non correlated to adaptation period }\end{array}$ & $3(1.66 \%)$ \\
symptoms & $12(6.66 \%)$ \\
$\begin{array}{l}\text { Early retrieval due to prolonged adaptation period } \\
\text { symptoms and rejection by the patient or }\end{array}$ & $2(1.11 \%)$ \\
$\begin{array}{l}\text { impossibility in proceed the balloon down setting } \\
\text { Malory Weiss syndrome }\end{array}$ & $1(0.55 \%)$ \\
$\begin{array}{l}\text { Gastric Ulcer leading to early retrieval } \\
\text { Gastric ulcer diagnosed during the treatment }\end{array}$ & $1(0.55 \%)$ \\
$\begin{array}{l}\text { without the necessity to remove the balloon Gas } \\
\text { production inside the balloon }\end{array}$ & \\
\hline
\end{tabular}

*Number of subjects and percentages.

Table 2. Baseline characteristics of the participants.

\begin{tabular}{ll}
\hline Characteristics & Total group $(\mathbf{n}=\mathbf{1 8 0})^{*}$ \\
\hline Age (years) & $40.36 \pm 10.15$ \\
Gender $(\mathrm{n} ; \%)$ Male Female & $62(34.44 \%) 118(65.56 \%)$ \\
Body weight $(\mathrm{kg})$ & $107.67 \pm 23.65$ \\
Body mass index $\left(\mathrm{kg} / \mathrm{m}^{2}\right)$ & $37.69 \pm 6.16$ \\
BMI Classes $(\mathrm{n}(\%))^{*}$ Overweight Grade I & $12(6.67 \%) 51(28.33 \%) 63(35 \%) 54(30 \%)$ \\
obesity Grade II obesity Grade III obesity & \\
\hline
\end{tabular}

*Mean values with their standard deviations; number of subjects and percentages.

$\mathrm{BMI}=$ body mass index 
Table 3. Nutritional parameters at baseline (day of IGB insertion) and at the end of the study (day of IGB removal).

\begin{tabular}{llll}
\hline & Total group $(\mathbf{n}=\mathbf{1 8 0})$ & Upward adjustment & Upward adjustment \\
\hline & & Yes $(\mathbf{n}=\mathbf{8 6})$ & No $(\mathbf{n}=\mathbf{9 4})$ \\
$\begin{array}{l}\text { Body weight }(\mathbf{k g}) \\
\text { Baseline }\end{array}$ & & \\
Final & $107.67 \pm 23.65$ & $108.66 \pm 25.12$ & $106.76 \pm 22.3$ \\
Reduction & $90.16 \pm 22.53^{*}$ & $90.41 \pm 23.39^{*}$ & $89.94 \pm 21.83^{*}$ \\
\% TWL & $17.51 \pm 11.67$ & $18.26 \pm 10.99$ & $16.83 \pm 12.28$ \\
BMI $\left.\mathbf{( k g} / \mathbf{m}^{2}\right)$ & $16.22 \pm 9.74$ & $16.81 \pm 9.09$ & $15.68 \pm 10.33$ \\
Baseline & & & \\
Final & $37.69 \pm 6.16$ & $38.26 \pm 6.56$ & $37.16 \pm 5.77$ \\
Reduction & $31.51 \pm 6.11^{*}$ & $31.55 \pm 6.11^{*}$ & $31.29 \pm 6.14^{*}$ \\
Excess weight $(\mathrm{kg})$ & $6.18 \pm 4.07$ & $6.51 \pm 3.91$ & $5.87 \pm 4.21$ \\
Baseline & & & \\
Final & $36.79 \pm 19.07$ & $38.15 \pm 20.15$ & $35.58 \pm 18.04$ \\
Reduction & $21.79 \pm 19.33^{*}$ & $19.89 \pm 18.45^{*}$ & $23.25 \pm 19.39^{*}$ \\
\% EWL & $15.00 \pm 10.67$ & $18.26 \pm 10.90$ & $17.54 \pm 11.38$ \\
\hline
\end{tabular}

${ }^{*} \mathrm{p}<0.0001$ for all comparisons between values at baseline and at the end of the study.

p $>0.05$ for all comparisons between groups with and without upward adjustment

$\mathrm{IGB}=$ intragastric balloon; $\mathrm{BMI}=$ body mass index; TWL $=$ total weight loss; $\mathrm{EWL}=$ excess weight loss

Figure 1. Dendogram chart showing the degree of similarity between the values of the average reduction of TWL, with and without adjustment of Spatz3(r).

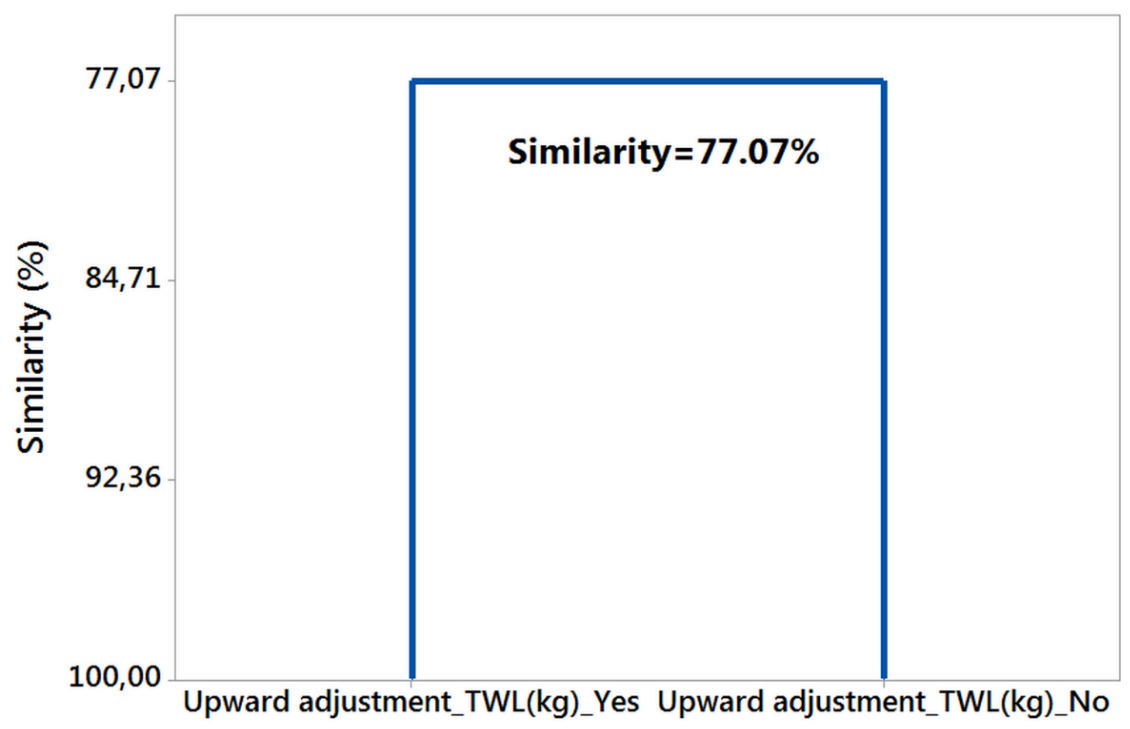

Figure 2. Box-Plot graph showing the intervals, mean, and median of the TWL reduction values, with and without Spatz3(R) adjustment, as well as the p-value $(95 \% \mathrm{CI})$, p-value $<0.05$ was considered to be significant. 


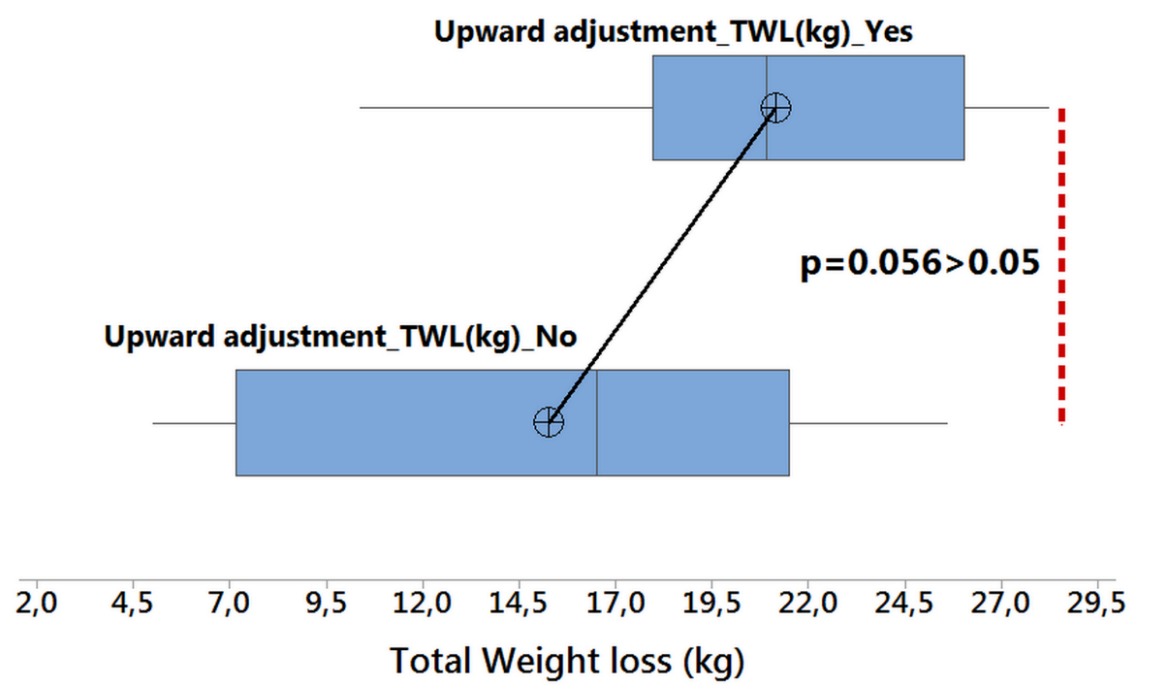

Figure 3. Dendogram chart showing the degree of similarity between the values of the average reduction of EWL, with and without adjustment of Spatz3ß.

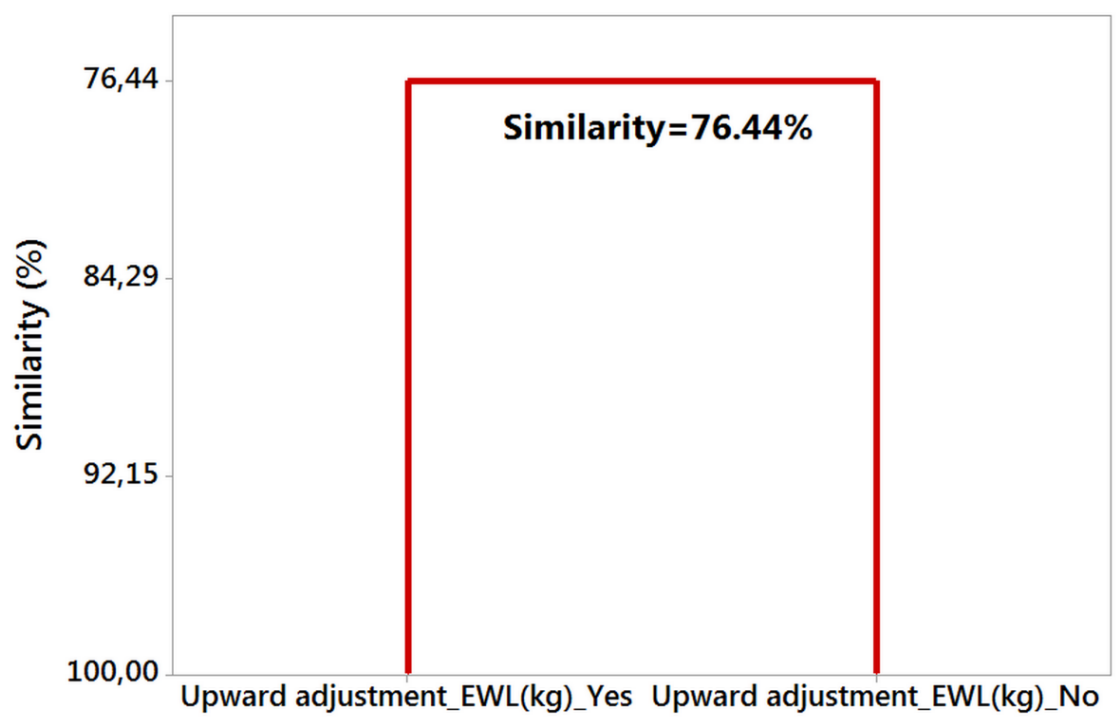




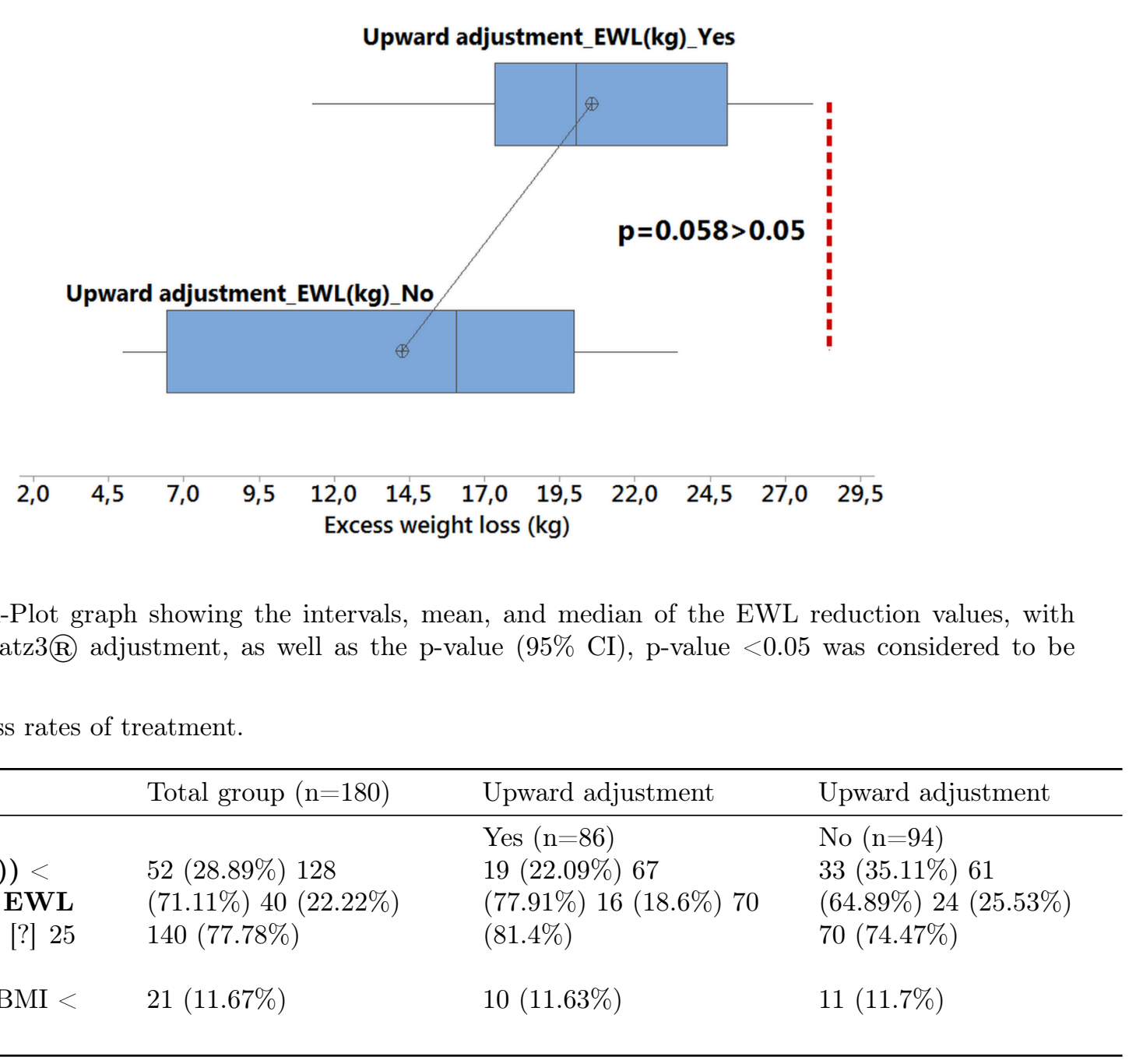

Figure 4. Box-Plot graph showing the intervals, mean, and median of the EWL reduction values, with and without Spatz3(R) adjustment, as well as the p-value (95\% CI), p-value $<0.05$ was considered to be significant.

Table 4. Success rates of treatment.

\begin{tabular}{|c|c|c|c|}
\hline & Total group $(\mathrm{n}=180)$ & Upward adjustment & Upward adjustment \\
\hline $\begin{array}{l}\text { \% TWL }(\mathbf{n}(\%))< \\
10 \%[?] 10 \% \% \text { EWL } \\
(\mathbf{n}(\%))<25 \%[?] 25 \\
\%\end{array}$ & $\begin{array}{l}52(28.89 \%) 128 \\
(71.11 \%) 40(22.22 \%) \\
140(77.78 \%)\end{array}$ & $\begin{array}{l}\text { Yes }(\mathrm{n}=86) \\
19(22.09 \%) 67 \\
(77.91 \%) 16(18.6 \%) 70 \\
(81.4 \%)\end{array}$ & $\begin{array}{l}\text { No }(\mathrm{n}=94) \\
33(35.11 \%) 61 \\
(64.89 \%) 24(25.53 \%) \\
70(74.47 \%)\end{array}$ \\
\hline $\begin{array}{l}\text { BMI (n (\%)) BMI < } \\
25 \mathrm{~kg} / \mathrm{m}^{2}\end{array}$ & $21(11.67 \%)$ & $10(11.63 \%)$ & $11(11.7 \%)$ \\
\hline
\end{tabular}

$\mathrm{TWL}=$ total weight loss, EWL $=$ excess weight loss, $\mathrm{BMI}=$ body mass index

Table 5. Body mass index (BMI) pre and post adjustable IGB treatment, \% Excess Weight Loss (\%EWL) and weight loss (WL) (kg) after upward adjustment (UA) in several studies and in the present study.

\begin{tabular}{|c|c|c|c|c|c|c|}
\hline Authors & $\mathrm{N}$ & BMI $\left(\mathrm{Kg} / \mathrm{m}^{2}\right)$ & BMI $\left(\mathrm{Kg} / \mathrm{m}^{2}\right)$ & BMI $\left(\mathrm{Kg} / \mathrm{m}^{2}\right)$ & $\%$ EWL (kg) & $\% \mathrm{TWL}$ \\
\hline & & Baseline & Removal & Reduction & & $(\mathrm{kg})$ \\
\hline $\begin{array}{l}\text { Machytka et } \\
\text { al }(2014)^{[6]}\end{array}$ & 77 & 37.2 & NI & $\mathrm{NI}$ & 40.1 & 8.2 \\
\hline $\begin{array}{l}\text { Brooks et al } \\
(2014)^{[14]}\end{array}$ & 73 & 36.6 & NI & $\mathrm{NI}$ & 45.7 & 9.4 \\
\hline $\begin{array}{l}\text { Genco et al } \\
(2013)^{[9]}\end{array}$ & 40 & 40.9 & 31 & 9.9 & 56.7 & NI \\
\hline $\begin{array}{l}\text { Machytka et } \\
\text { al }(2011)^{[8]}\end{array}$ & 18 & 37.3 & NI & NI & 48.8 & 7 \\
\hline
\end{tabular}




\begin{tabular}{lllllll}
\hline Authors & $\mathrm{N}$ & $\mathrm{BMI}\left(\mathrm{Kg} / \mathrm{m}^{2}\right)$ & $\mathrm{BMI}\left(\mathrm{Kg} / \mathrm{m}^{2}\right)$ & $\mathrm{BMI}\left(\mathrm{Kg} / \mathrm{m}^{2}\right)$ & $\% \mathrm{EWL}(\mathrm{kg})$ & $\% \mathrm{TWL}$ \\
\hline $\begin{array}{l}\text { Russo et al } \\
(2016)^{[27]}\end{array}$ & 10 & $\mathrm{NI}$ & 32 & $\mathrm{NI}$ & $\mathrm{NI}$ & $\mathrm{NI}$ \\
$\begin{array}{l}\text { Fittipaldi- } \\
\begin{array}{l}\text { Fernandez et } \\
\text { al (This study) }\end{array}\end{array}$ & 86 & 38.66 & 7 & 6.51 & 52.7 & 16.81 \\
\hline
\end{tabular}

*IGB $=$ intragastric balloon, $\mathrm{NI}$ - not informed 